\title{
Market transformation of energy-efficient motor technologies in the EU
}

\author{
Anibal T. de Almeida ${ }^{\mathrm{a}}$, Paula Fonseca ${ }^{\mathrm{a}, *}$, Hugh Falkner ${ }^{\mathrm{b}}$, Paolo Bertoldi ${ }^{\mathrm{c}}$ \\ ${ }^{a} I S R$, Department of Electrical and Computer Engineering, University of Coimbra, Pólo II, 3030 Coimbra, Portugal \\ ${ }^{\mathrm{b}}$ ETSU, Harwell Didcot, Oxfordshire OX11 ORA, UK \\ ${ }^{\mathrm{c}}$ European Commission, Joint Research Center, TP 450, I-21020 Ispra (VA), Italy
}

\begin{abstract}
Based on a recent study carried out for the European Union (EU), this paper briefly characterizes the motor electricity end-use consumption in the industrial and in the services sectors, in the EU countries, and estimates the identified electricity savings potential with the application of energy-efficient motor technologies, namely energy-efficient motors, variable speed drives and efficient enduse devices (pumps, fans and compressors). Additionally, there is a detailed presentation of the barriers for the penetration of energy-efficient motor systems, which have been identified in the field, as well as an extensive description of the measures to overcome those barriers and promote energy-efficient motor systems. (C) 2002 Elsevier Science Ltd. All rights reserved.
\end{abstract}

Keywords: Electricity end-use efficiency; Motor systems; Energy-efficient motors

\section{Introduction}

Most of the electricity consumed in industrialized countries is used in electric motor applications. Based on a recent field characterization study in the European Union (EU), motors are responsible for $69 \%$ and $38 \%$ of the total electricity consumption in industry and in the services sector, respectively (Project Report, 2000).

With the field characterization it was possible to collect reliable data on motor electricity use, which was the basis for the assessment of the savings potential. Technical electricity savings potential of about 107 and $37 \mathrm{TWh}$, in the industrial and in the services sectors, respectively, has been identified. These values are a conservative estimate of the electricity savings potential, because there are other measures for improving the motor system efficiency which have not been assessed. These measures include, for example, the application of low-cost efficiency measures which do not require sophisticated technology, such as improving maintenance practices, reducing waste, etc. Drivetrain, transmission systems and motor repair present other possibilities for efficiency improvements. 672

*Corresponding author. Tel.: +351-39-796-218; fax: +351-39-406-

E-mail address: pfonseca@isr.uc.pt (P. Fonseca).
For the assessment of the electricity savings potential with the application of energy-efficient motors (EEMs), variable speed drives (VSDs) and efficient end-use devices, two different scenarios have been considered: the technical and the economic savings potential. While the application of EEMs and efficient end-use devices is in the vast majority of cases cost effective, in the application of speed controls there are some situations in which the application of VSDs is not economically justified.

Although there is a large potential for energy savings with EEMs, VSDs and efficient end-use devices, these technologies have not yet been widely adopted. Since electric motors are an integral part of any productive system, different actors and several barriers have to be addressed when designing policy measures for tapping this huge electricity savings potential. For this purpose, the most important market transformation strategies are addressed in this paper.

\section{Field characterization of motor electricity use}

The most important industrial sub-sectors and the services sector in the EU have been characterized with field studies. The surveyed industrial sub-sectors represent $72 \%$ of the total industrial electricity consumption 
in the EU. These sectors are non-metallic minerals, paper-pulp-print, food-beverage-tobacco, chemical, iron-steel, and machinery-metal. In order to gather as much information as possible with high level of accuracy, extensive audits, site visits and questionnaires have been carried out in each of the sectors. Based on the field characterization carried out in Portugal, Germany, France, United Kingdom and Italy, the collected data were then extrapolated for the EU.

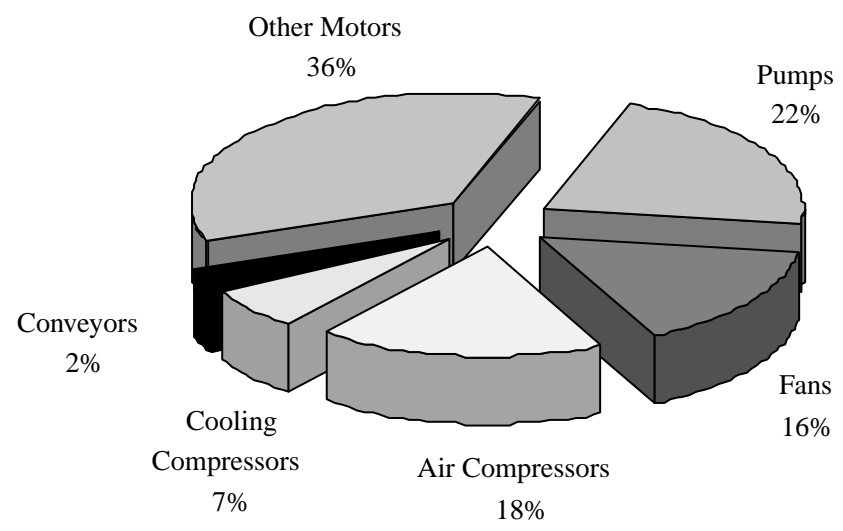

Fig. 1. Share of motor electricity consumption by type of end-use, in the industrial sector.

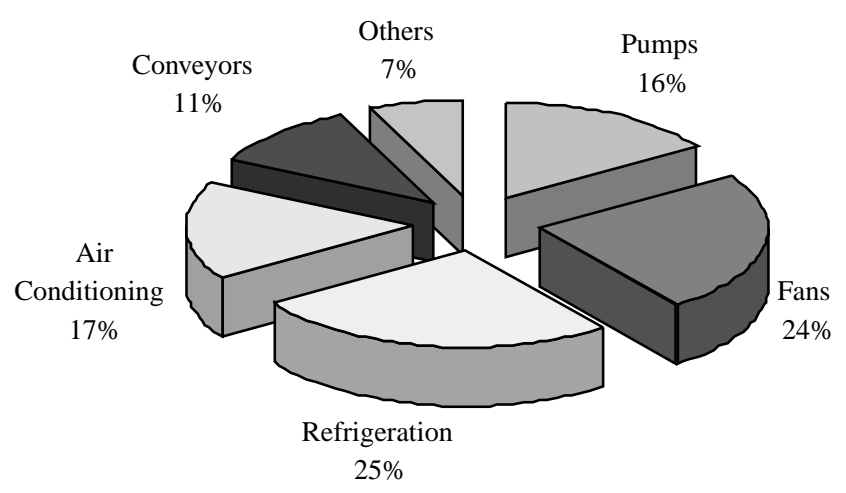

Fig. 2. Share of motor electricity consumption by type of end-use, in the services sector.
All the data collected in the field was characterized by type of load and by motor power range. This is very important because the efficiency difference between standard and EEMs is larger in small motor sizes than in the large sizes, which is most relevant for the calculation of the electricity savings potential using EEMs.

Controllable loads such as pumps, fans and compressors represent an important share in the total motor electricity consumption, representing $62 \%$ and $83 \%$ in the industrial and in the services sectors in the EU, respectively. Figs. 1 and 2 show the share of motor electricity consumption by end-use application in the industrial and in the services sectors in the EU, respectively (Project Report, 2000).

Figs. 3 and 4 show the motor electricity consumption, the installed capacity, and the average number of operating hours by power range, in the industrial and in the services sectors in the EU, respectively.

The field characterization analyzed every sub-sector in detail in terms of electricity consumption, number of operating hours, average load factor, as well as number of motors by power range and by type of motors. As it is generally assumed, the dependence of the operating hours on the size of the motor in the industrial sector ("larger motors have longer operating hours") was one finding of the field characterization. Another important finding of the field characterization was that motors are oversized in a significant part of the applications both in industry and in the services sector, which leads to a significant drop in efficiency (particularly for motors whose load is bellow $50 \%$ of the rated power) and leads to a low power factor, with all the associated inefficiency problems (Nadel et al., 2001).

\section{Potential electricity and carbon savings}

Motor system performance depends not only on the motor itself, but also on each element of the motor

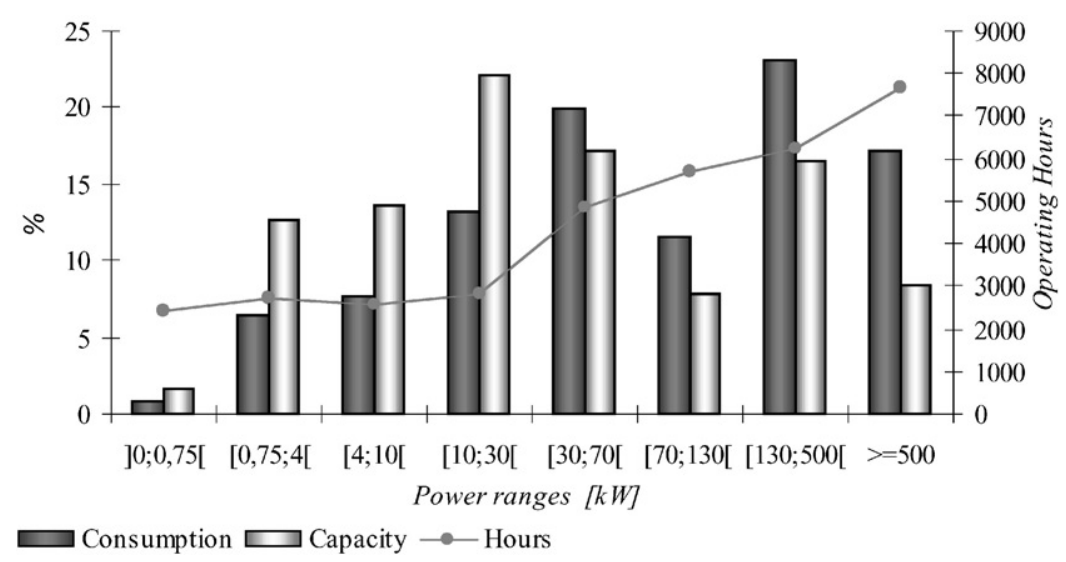

Fig. 3. Installed nameplate motor capacity, electricity consumption (as a percentage of the total industrial motor usage) and average operating hours by power range in the industrial sector. 


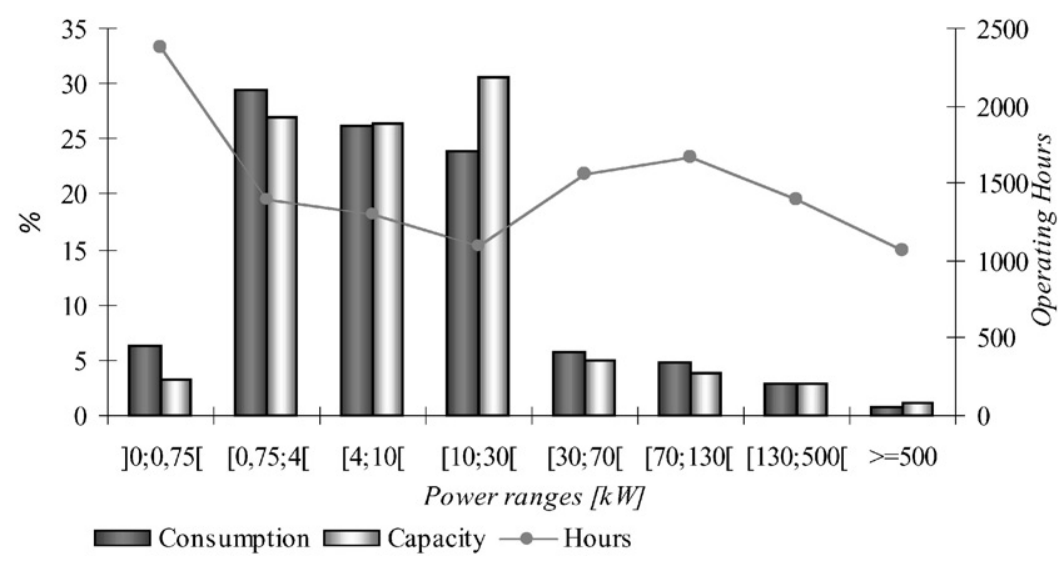

Fig. 4. Installed nameplate capacity, electricity consumption (as a percentage of the total industrial motor usage) and average operating hours by power range in the services sector.

system. From a technical point of view, the potential efficiency improvements can be divided into:

- improvement of system components (efficient motors, transmission, end-use devices);

- improvement in overall system design and system operation (good design of the motor system, proper sizing of motor, pump, fan and compressor, system switch off when idle, proper maintenance, load management and cycling, etc.);

- integration of speed controls (VSDs) in the situations with variable load requirements.

This paper only addresses the potential savings with EEMs, VSDs and efficient end-use devices. The potential electricity savings would be larger if other efficiency improvements were considered. Therefore the estimated savings potential are conservative. In order to estimate the electricity and carbon savings potential, the time horizon of 2015 was used. The annual average growth rates of the electricity consumption up to 2015 , in the industrial and in the services sectors in the EU were assumed to be $1.2 \%$ and $1 \%$, respectively (European Commission, 1996a).

For the assessment of the electricity savings potential with the application of EEMs, efficient end-use devices (efficient pumps, efficient fans and efficient compressors), VSDs, two different conditions have been considered: the technical savings potential and the economic savings potential. The technical potential represents the energy savings potential that can be achieved by the application of the measure to all the available opportunities, irrespective of the cost effectiveness of the measure. The economic potential represents the energy savings that can be achieved when the measure is only applied to cost effective opportunities. The evaluation of the cost effectiveness of the measures was based on the cost of saved energy. Additionally, life cycle cost (LCC) analysis has also been carried out.

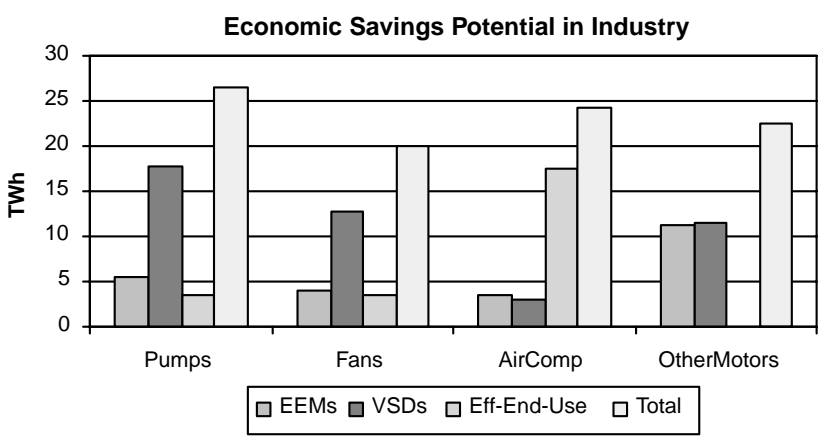

Fig. 5. Economic savings potential in industry.

The application of EEMs and efficient end-use devices appeared to be cost effective in all power ranges. Therefore, the economic potential is equal to its technical potential, which amounts to $47 \mathrm{TWh}$ in industry and to $14 \mathrm{TWh}$ in the services sector. In the case of VSDs, there are some situations in which the application of speed controls is not economically attractive, especially in the lower power ranges. In the industrial sector the proportion of applications in which VSDs are cost effective is larger than in the services sector, in which the number of operating hours is significantly less. The higher cost of electricity in the services sector only partially compensates the reduction in operating hours. The technical savings potential due to the application of VSDs reaches 71 and $25 \mathrm{TW} \mathrm{h}$ in industry and in the services sectors, respectively, and the economic savings potential reaches 45 and $9 \mathrm{TWh}$. Figs. 5 and 6 show the economic potential savings by type of load, in the industrial and in the services sectors, respectively.

\subsection{Life cycle costs}

LCC is the sum of purchase price (PP) and operating cost over the life cycle of the product. LCC links purchasing decisions to their long-term impact on 


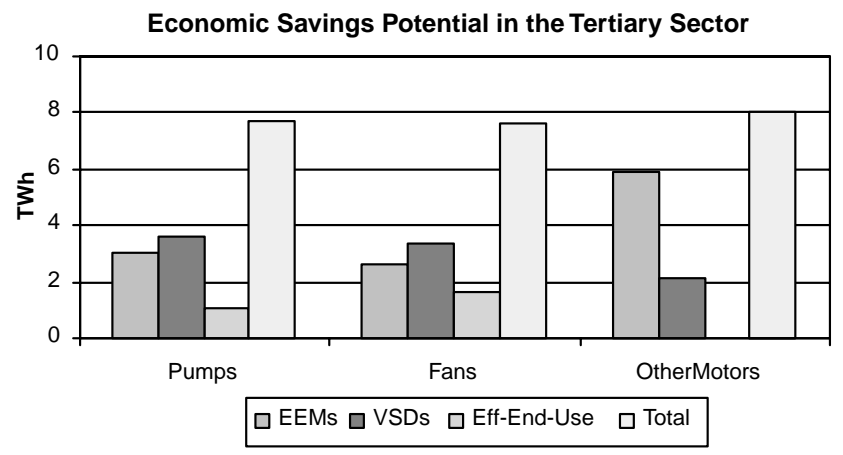

Fig. 6. Economic savings potential in the services sector.

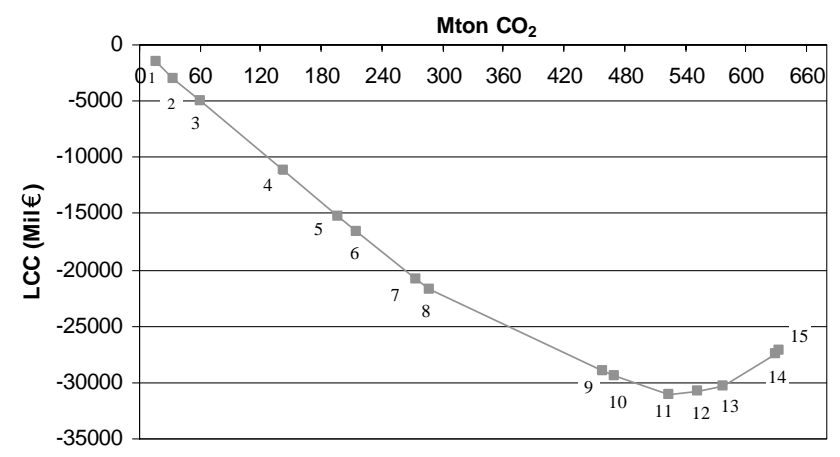

Fig. 7. LCC and $\mathrm{CO}_{2}$ savings in industry (see Table 1 for identification of measures).

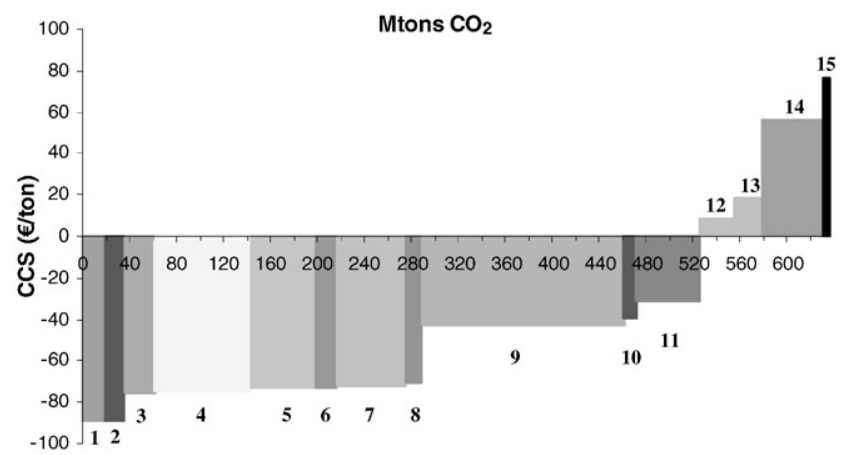

Fig. 8. CCS and $\mathrm{CO}_{2}$ savings in industry (see Table 1 for identification of measures).

energy consumption, making the cost of a product visible over its whole lifetime (Final ECCP Report, 2001).

Figs. 7 and 8 show the LCC and the cost of carbon savings (CCS), respectively, as a function of lifetime carbon savings, for each efficiency improvement option in the industrial sector. Table 1 lists the evaluated motor improvement options in the industrial sector.

Figs. 9 and 10 show the LCC and the CCS, respectively, as a function of lifetime carbon savings, for each efficiency improvement option in the services sector. Table 2 lists the evaluated motor improvement options in the services sector.

For the assessment of the carbon savings potential, it was assumed to be $0.4 \mathrm{~kg} \mathrm{CO} / \mathrm{kWh}$, which is the
Table 1

Technological improvement option in the industrial sector

Efficient pumps

Efficient fans

EEMs in pumps

VSDs-e in pumps

EEMs in others

EEMs in fans

VSDs-e in fans

EEMs in compressors ${ }^{\mathrm{a}}$

Efficient compressors

VSDs-e in compressors

VSDs-e in others

VSDs-ne in pumps

VSDs-ne in fans

VSDs-ne in other motors

VSDs-ne in aircompressors

${ }^{\mathrm{a}}$ The efficient compressors savings also include air leaks reduction (Peter Radgen and Edgar Blaustein, 2001).

Table 1

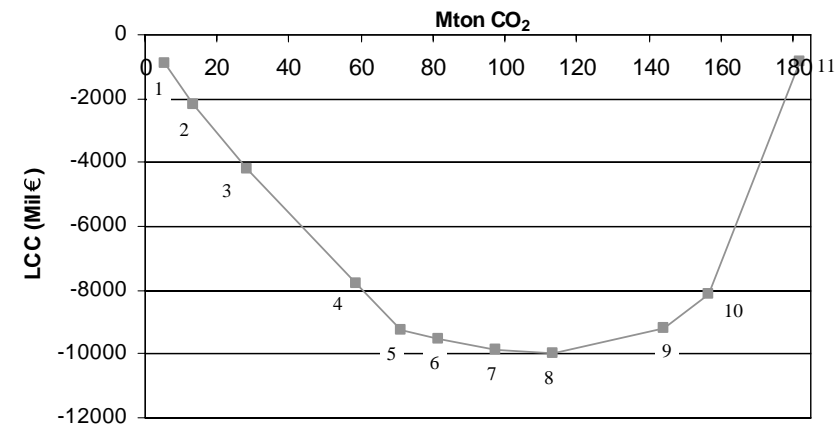

Fig. 9. LCC and $\mathrm{CO}_{2}$ savings in the services sector (see Table 2 for identification of measures).

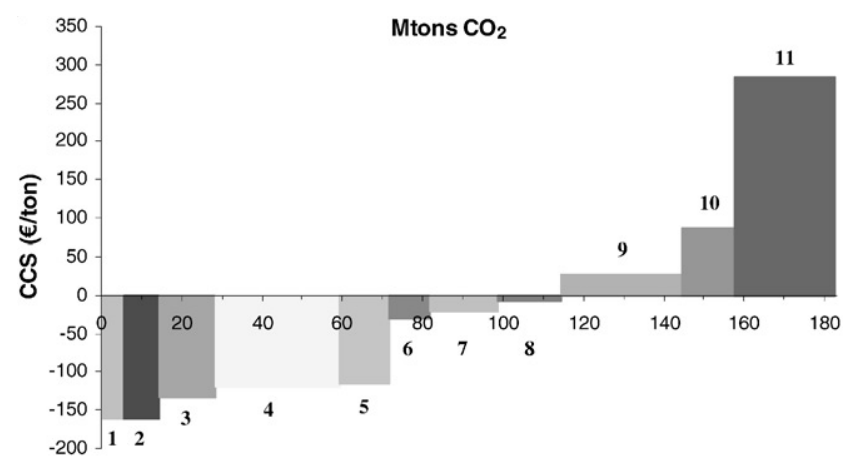

Fig. 10. $\mathrm{CCS}$ and $\mathrm{CO}_{2}$ savings in the services sector (see Table 2 for identification of measures).

approximate carbon emissions value of combined cycle gas turbine power plants, taking also into consideration the transmission and distribution losses.

\section{Barriers}

Discussion on barriers to energy efficiency in general is covered in depth in many existing documents 
Table 2

Technological improvement option in the services sector

\begin{tabular}{lr}
\hline Efficient pumps & 1 \\
Efficient fans & 2 \\
EEMs in pumps & 3 \\
EEMS in fans & 4 \\
EEMs in others & 5 \\
VSDs-e in pumps & 6 \\
VSDs-e in fans & 7 \\
VSDs-e in others & 8 \\
VSDs-ne in pumps & 9 \\
VSDs-ne in fans & 10 \\
VSDs-ne in others & 11 \\
\hline
\end{tabular}

Table 2

(European Commission, 1996b; Commission of the European Communities, 2000; Reddy, 1991; Macro Consulting, Inc., 1994), and so this paper focuses much more closely on the very real and often quite distinctive barriers affecting the design and implementation of motor system efficiency measures, which have been identified in the field, namely:

- Who makes the various motor system purchases and management decisions?

- What criteria do these individuals apply to motor system purchase and management decisions?

- Are staff managers, who usually are more concerned with ensuring the continuity in the manufacturing process rather than with the efficiency of motor systems, aware of the benefits of improving energy efficiency?

These are the most common barriers that are preventing the adoption of EEM systems. Other barriers are also presented in this paper and market transformation strategies are suggested in order to promote EEM technologies.

While there is a high level of awareness of the use of EEMs, VSD and efficient end-use devices for saving energy, in many situations, lack of more detailed knowledge prevents the application of energy-efficient technologies. There are several quite minor downsides to the use of these technologies, but these issues are often got out of proportion and hence deter use of these products. In some applications economics dictate that the payback will never be adequate to justify investments. This is largely a case of waiting for the relative costs to change in favor of making investments (this is likely to happen in some VSD applications). Internal conflicts and pressures were seen as being much more important than the technical and economic barriers already mentioned.

\subsection{Awareness of the options}

While there is a high level of general awareness of the use of EEMs, VSDs and efficient end-use devices for energy saving, on many sites there was a difficulty translating this into possible actions on their own site. In addition, there is still skepticism of the energy savings that can be made, although as EEMs and VSDs have become more widely accepted, this scepticism is certainly much less than in the past. For some motor users the excess of energy saving information from different sources, sometimes apparently conflicting, and the inappropriateness of some energy saving tools/ publications, often too complicated or too basic, acts as a further deterrent.

\subsection{Technical options}

\subsubsection{Variable speed drives}

There is considerable coverage in the technical press about some topical "problem" issues. This has been exacerbated by a failure of the VSD industry to have a single concerted view on these subjects, and has led to a lot of generally unwarranted concerns, such as:

- The generation of harmonics into the mains supply and electromagnetic interference into susceptible equipment. In practice this is actually rarely a problem, and low-cost solutions are available to overcome possible problems and to comply with the legislation.

- Older motors with lower grade insulation systems may suffer earlier failure due to faster voltage rates of rise of VSDs (particularly in the pulse width modulation (PWM) synthesized waveform) (Project Report, 2001). Here, responsible VSD vendors will always check and make recommendations on the suitability of existing motors for the fitting of VSDs, and again solutions are available to overcome the problem in most cases.

- A very occasional problem is that a high-frequency current is induced in the motor shaft, which can return through the motor stator to set up a current sufficiently large to cause bearing failure. At greater cost, insulated bearings can be specified which overcome this problem.

- Early VSDs had a reputation for being unreliable, and so some engineers with experience of these units still have a natural reluctance to buy further VSDs.

Safety concerns in some safety critical industries, especially petro-chemicals (particularly dealing with the danger of uncontrolled over-speed), unauthorized personnel access (that could cause major damage by altering settings on VSDs), complicated commissioning of VSDs, cost of commissioning (particularly in continuously operating plant where downtime means loosing thousands of Euros), cost of control optimization, and the falling prices of VSDs (while the reduction 
in price may be good, it does mean that the technical effort the supplier can spend in helping to find and offering system designs for likely applications is falling fast) have also been identified as important barriers for VSDs installation.

\subsubsection{Energy-efficient motors}

Induction motors are very much their own "worst enemy" in that they are reliable, quiet, and will survive with little or no maintenance. In addition, the International Electrotechnical Commission (IEC) standard designs mean that there is practically very little differentiation between different motor brands, which means that it is a very cost conscious, commodity market. While efficiency is used by some manufacturers to differentiate their products, even in the few companies who are open to the idea of paying more for these products, there are many practical reasons as to why uptake may be far less than expected.

Motors are seen as being of low interest by many non-technical personnel and the relatively small possible improvements in efficiency seem just too low to get very excited about. Besides, when considering several alternatives for motor load applications, other factors such as availability, service, known brand name, stocks of older "salvaged" motors, etc. are usually more important than efficiency. Although first cost is often regarded as being the main barrier, many users actually consider these other factors to be of at least as the same importance. Additionally, motor users want some confidence that an efficient equipment really will make a difference in power consumption, which ideally means a before and after measurement of power. But practically it is impossible to measure the efficiency of an existing motor, and so reliance on catalogue data (where available) is needed.

Another important constraint is the higher operating speed of EEMs. The lower slip and hence higher speed of EEMs means that they will draw more power (although, because they are doing more work and they have lower losses, they are still more efficient). If advantage cannot be taken of this extra work associated with the higher operating speed, then the system efficiency will be reduced, particularly in motor applications driving a fan or pump. Alternatively, the final drive speed can be adjusted by altering pulley ratios or by having external controls. In cases in which EEM suppliers have not warned customers in advance, a simple "before" and "after" current comparison can cause the customer to become very upset and hence deterred from further purchases of EEMs. Other constraints, like the user motor procurement specifications, longer lengths of EEMs, repair of failed motors and oversizing can also hinder the adoption of EEMs.

\subsubsection{Switch off}

While not a central part of this study, some of the barriers to the apparently simple measure of switching off the plant when it is not needed give a very useful insight into some other difficulties associated with making electricity savings. The huge range of opportunities, often specific to a particular piece of equipment, means that promoting such an option on anything other than a simplistic basis is hard. Additionally, the low cost of the technology needed, e.g. time-switches, means that suppliers cannot afford to spend much time in promoting the use of these technologies, or giving detailed applications advice. There is also reluctance to switch equipment off since there is always a worry that equipment will not start again when needed or the start up time will be too long. In addition, the wear caused at each switching on and off of equipment (particularly larger motors with high inertia loads) is a real concern, although it can be cost effectively overcome by the use of soft starting equipment.

\subsection{Economic barriers}

There are several reasons why energy saving projects may be rejected for economic reasons: insufficient running hours to give an acceptable payback, high ratings of equipment leading to higher initial costs that will adversely effect the payback, equipment with limited lifetime, earlier bad experiences of energy saving products or applications that have not delivered the expected benefits, etc.

\subsection{Internal conflicts}

While personnel in different parts of an organization will usually acknowledge that it makes sense to purchase energy saving equipment, in practice there are many internal pressures and conflicts which make implementation very difficult:

- Because engineers are weak at putting over their case for investment in terms which the decision maker is familiar, many engineers complain that their sound investment plans have been rejected by accountants or other decision makers.

- Splitting of budgets means that very often one budget holder will be asked to save money for another budget holder. Even when there is a mutual desire to find a workable answer, split budgets are often the reason for investments not being made.

- The best energy saving opportunities are often on support services, such as steam, compressed air, water, heating, ventilation and air conditioning (HVAC), cooling systems, etc., in which sizable plant is running for long hours, often with a widely varying demand. Such services are often regarded by the users 
as free, and seen simply as a ("fixed") factory overhead.

- There is little incentive to make energy savings if there is even a small risk of this leading to service failure.

- Outsourcing of functions, such as new equipment design, means that vital skills may be lost from the organization, and outside designers are usually driven by first cost. Energy costs are unlikely to be of so much interest to them.

- Unless energy costs are allocated to individual production areas, there will be little incentive to reduce wastage, and feedback on the success of energy saving measures will not be possible.

- Reducing energy costs may result in a reduced budget for the following year, which is an active disincentive to take action.

- Lack of time means that verification of actual energy savings achieved is rarely made.

- While very useful, senior management commitment to energy saving will not alone be sufficient. Clear action plans, which can be implemented, are also required. Conflicting pressures will mean that wellmeaning commitments are soon forgotten.

- Maintenance is of very high priority, and any energy saving product that may have even a small negative effect on equipment reliability will therefore be unlikely to win approval.

- Even when energy managers are in place, they very often have to also take on other responsibilities such as health and safety or quality assurance which have to take priority because they have legislative back-up.

\subsection{Market structure}

Around $80 \%$ of low-voltage $(400 \mathrm{~V}$, three-phase) induction motors are sold through Original Equipment Manufacturers (OEMs), who since they do not pay for ongoing running costs, find themselves under great pressure to offer lower cost motors and avoid the use of VSDs. This is a very significant problem, and ultimately it is up to purchasers to stimulate the availability of improved efficiency equipment by demanding it from suppliers who otherwise have little incentive to make it available.

\section{Strategies/recommendations to motor market transformation}

As it can be seen in Figs. 5 and 6, there is a large potential for electricity savings by addressing the efficiency of the entire motor system, both in industry or in the services sector, including motor efficiency, use of VSDs, pump systems efficiency, ventilation system efficiency and compressed air systems efficiency.
Experience of many energy saving initiatives around the world shows that the most successful programs to achieve the potential savings are based on a combination of technical information, financial incentives, voluntary agreements, and in some case the use of regulation.

Much has been published elsewhere concerning the issue of financial incentives (or penalties) for encouraging the uptake of energy saving equipment, and so this paper will only concentrate on motor specific issues (Paolo Bertoldi et al., 2000). It presents some measures, which can encourage motor system market transformation, in order to achieve the identified electricity savings potential with EEMs, VSDs and efficient end-use devices in industry and in the services sector.

\subsection{Education and training}

More education on energy efficiency is needed on many fronts. With just a few exceptions, the bulk of the audience, which will be reached by a motors-based energy saving initiative is technical personnel - typically plant engineers, maintenance engineers, occasionally production personnel or energy managers. These will also be the individuals who will identify and then win funding for energy saving projects. They need to have promotional/educational materials and schemes, which will address their differing needs at each stage on the way to implementing successful energy saving projects, including:

- becoming interested in saving energy;

- receive sound technical information on energy saving options;

- identify possible energy saving projects;

- write and present proposal(s);

- implement project(s); and

- estimate energy savings made.

This information gap should be filled through several means, namely:

\subsubsection{Media}

There are various techniques to raise interest in energy savings, including advertising, trade press releases, direct mail, electronic mail, web-sites and attendance at exhibitions. The mix of these depends mainly on the available budgets, with care taken to examine the possible impacts.

\subsubsection{Publications}

A selection of materials is necessary from short and simple introductory leaflets and brochures to guides, handbooks, journals and software giving much more detailed technical information needed to satisfy more experienced personnel. These should be issued and 
distributed by manufacturers, trade associations, distributors, energy agencies, etc.

\subsubsection{Training and workshops}

Short practical information and training sections are targeted at system suppliers, engineering consultants, OEMs, installers, and dealers. To a limited extent, endusers may be reached, e.g. in short afternoon workshops on prime business concerns. Experiences with short workshops show they attract much interest without much cost.

\subsubsection{Dissemination}

Educational materials can be disseminated not only through existing energy agency databases and via the media (paper-based products, software programs and Internet information), but also tremendous gearing can come from the use of third parties such as trade associations and equipment suppliers. Equipment suppliers in particular value the independence of the produced materials, although here it is important that brand names are not included in materials if rival suppliers are going to disseminate information.

\subsection{Provide technical assistance}

\subsubsection{Decision support tools}

User-friendly software tools are required for more standardized comparison of efficiency and economics of system configurations. Many manufacturers already have software tools. However, these tools are not independent, use different assumptions and rely on the quality of data input, which for the case of VSDs is not known to sufficient accuracy to give sufficiently accurate answers. Therefore, these tools have limited impact on the dissemination of VSDs. Independent software tools may be far more effective if the following features are included:

- More standardization in assumptions and calculation methods.

- Independence from specific manufacturers/suppliers.

- Supported and used by the VSD manufacturers. The cost effectiveness of this software will depend on becoming more or less a standard in these channels (rather than only a tool for a few specialized consultants). Suppliers and installers will be the main users of the software in their contacts with the clients. End-users will generally rely upon the suppliers.

Comparability of system performance is more important than detailed technical information. The software on compressed air systems is established along these lines and is becoming more and more a standard. There are various systems that may form the base for such tools (Compressed Air Challenge).

\subsubsection{Databases}

These are support tools for product selection, such as EURODEEM (http://iamest.jrc.it/projects/eem/eurodeem.htm) for motors that help users to select particular equipment for an application. Particularly useful for products such as motors where there are many different types available and where an independent source of data will speed up selection of the most efficient products, and give an easy way of comparing lifetime costs. There is a need to update the EURODEEM database and extend it to VSDs, and end-use devices.

As an example, the pumps extension to the EURODEEM database of motors will include several tools to assist users in pump selection:

- A simple guide to manufacturers of pumps for different applications.

- A database allowing users to compare the efficiency of different pumps for a specified duty. This database tool could automatically calculate the procurement line efficiency required for the duty, showing clearly which pump exceeds the line.

\subsubsection{On-site assessment and assistance}

Measurement campaigns to give motor users a short description of their savings potential need to be taken. Energy saving publications frequently use comprehensive measurements to ensure the reliability of the figures presented, but in practice most site personnel will only have the time and resources for much simpler measurements. This is a very important area, which can cause a lot of difficulties, including:

- What to measure (not just electrical power, but often also physical quantities such as flow or pressure).

- Required accuracy level of the measurements.

- Over what time period measurements need to be taken.

- What level of measurements will be cost effective.

- When power meters are unavailable or too difficult to connect up, how to make estimates of power from current readings.

Site visits: On-site advice from independent experts, fully or partly paid for by energy agencies, will help to start and to maintain the search for and momentum behind the identification and implementation of energy saving projects.

Energy audits: Detailed engineering analysis can be provided by several industrial audit programs operated by utilities, regional energy offices, universities, and private motor distributors. This procedure could increase awareness of electricity consumption and foster future measures to improve the efficiency situation. 


\subsubsection{Writing and presenting proposals}

Having identified particular projects, funding must be sought from elsewhere in the organization. Too often a project will fail at this late stage because the project is poorly presented or presented in terms with which the recipient is not at ease. Training in creating and presenting proposals should therefore be a key element in any energy saving campaign.

\subsubsection{Demonstration projects and pilot actions}

One key factor that limits the adoption of energyefficient technologies is the skepticism about their viability. People doubt about their durability, performance and real savings. There already is a lot of demonstration projects and case studies on the application of EEMs and VSDs with different applications (Best Practice Programmes in the UK, or the International Center for the Analysis and Dissemination of Demonstrated Energy Technologies-CADDET (http://www.caddet-ee.org)), but demonstration projects aimed at new technologies as well as to make more accessible the results of existing actions are needed. Demonstration provides a forum between promoters and end-users that can give some feedback to promoters about end-users needs and wants.

\subsubsection{Life cycle costs}

LCC is one of the favorite and most expressive methods used to compare effectiveness of improvements. It links purchasing decisions to their long-term impact on energy consumption. LCC facilitates "Challenge" type programs, in that it allows management to demonstrate that environmentally optimal decisions are also economically optimal. LCC is a concept that makes the cost of a product visible over its whole lifetime.

LCC is the sum of PP and operating cost over the life cycle of the product:

$\mathrm{LCC}=\mathrm{PP}+\mathrm{PWF}\left(\mathrm{LC}, i_{\mathrm{r}}\right) \mathrm{OC}$,

$\operatorname{PWF}\left(n, i_{\mathrm{r}}\right)=\frac{\left(1+i_{\mathrm{r}}\right)^{n}-1}{\left(1+i_{\mathrm{r}}\right)^{n} i_{\mathrm{r}}}$

$(\mathrm{PWF}=$ present worth factor; $n=$ number of years; $i_{\mathrm{r}}=$ discount rate; and $\mathrm{OC}=$ annual operating cost).

In the case of pumps, there is already available a guide to LCC analysis for pumping systems (Pump Life Cycle Costs, 2000).

\subsection{Financial tools}

\subsubsection{Tax incentives}

Reducing value-added tax (VAT) on efficient equipment and accelerated depreciation on equipment, e.g. with VSDs, would be very effective measures to promote efficiency.
Subsidies and tax incentives are being used throughout the EU. In some cases, the energy sector provides incentives for VSD systems. There are some applications where VSDs are economically attractive. Subsidies and tax incentives would render this even more attractive. However, it should be considered that subsidies might increase the budget for technical departments and in some cases may raise attention from management. If properly used in decision-making, in convincing the management, they may have a significant role in accelerating the dissemination in initial phases of market development. The schemes should be easy and transparent to be effective.

Subsidies may be considered as a short-term measure in stimulating OEMs and system suppliers in offering improved services and integrated systems. They may enhance joint actions of a suppliers sector.

\subsubsection{Procurement}

Co-operative procurement involves forming a buyer group that defines performance requirements for improved energy-efficient systems and subsequently challenging the equipment supply sector in offering these services in a cost competitive way. An influential buyer group may jointly offer a sufficiently attractive market perspective for suppliers to meet the challenge. The perspective also includes demonstration effects to other potential buyers.

For VSDs, procurement does not seem to be cost effective since efficiency in VSDs is already high (Project Report, 2001). However, for integrated motor systems, procurement may be a trigger for several OEM sectors. A procurement level approach for pumps is recommended. This would consist of plotting the best efficiencies and a "mean-line" of efficiencies based on data collected from many manufacturers. On the one hand, the procurement level would give the user a clear guidance on the efficiency of pump they are considering compared to the best efficiency pump of the same type. Manufacturers, on the other hand, will have the opportunity of comparing the best efficiencies of their pumps with others makes, and may decide to improve their pump designs.

\subsubsection{Contests and awards}

Contests and awards is a way to honor the efforts of manufacturers, users, or other involved organizations, to improve system efficiency (e.g. US Energy Star (Energy Star Award Rules and Instructions, 2000)).

Motor systems awards should not only include the improvement of equipment but should be concentrated also on the system interactions. Thus, for a suitable award there are two possible approaches, both focusing proper system design:

- Award for the best system design, corresponding to the definition of theoretical user's need. 
- Awarding the design of existing and implementing systems.

For VSDs, the marketing value of an award could provide an extra drive for system suppliers and installers to improve system design through integration of speed control.

\subsubsection{Payment by savings}

Another market mechanism for improving energy efficiency involves the development of the Energy Service Company (ESCO) industry. Energy service companies are often privately owned, non-regulated organizations, which contract with a utility or an enduser to assess, finance and install energy conservation measures. The financial mechanism used by ESCOs for encouraging the use of their services is performance contracting. The ESCO takes as payment a share of the energy cost reduction, based on either engineering estimates or measurements.

\subsubsection{Outsourcing}

Outsourcing permits companies to delegate a function to specialized energy services providers, under a contract, which specifies quality of service, reliability and cost. However, some contracts do not address possible energy savings. This is the case when electricity consumption is paid for by the company rather than by the service provider. Thus, the service provider does not benefit from efficiency improvements. Public action could be useful to help potential users of outsourcing services to better contractualize the delivery of service, namely by taking into consideration the following issues:

- Monitoring the effects of case studies and making the effects visible (as a pilot action).

- Facilitating the elaboration of guidelines for outsourcing, e.g. on what to be included, how and what to be measured, etc. This makes outsourcing more transparent to end-users, and lowers the cost of suppliers.

- Facilitating selected sectors in defining and agreeing upon "performance indicators". This may be done, e.g., by representative groups of clients and suppliers of the selected sectors. Where relevant, an independent third party may be involved in control measurements.

Such limited pilot actions could be cost effective, when carried out as extension of the EU Motor Challenge Programme (MCP) (Motor Challenge Programme). The pilot action could include following steps: forming a potential buyer group, defining the contours and performance criteria for the services, elaborating a prospectus with typical end-use situations, establishing criteria for the suppliers, tendering, selection, contracting, evaluation and dissemination. Rather homogeneous and concentrated sectors for a pilot action may be banks, government buildings, or applications in industry such as compressed air.

\subsubsection{Leasing}

It is unlikely that motors or VSDs will be leased, but some packaged OEM products, air compressors in particular, are commonly leased. Under such arrangements where the equipment has a clear monthly charge, it is very appropriate to also consider the monthly charge for electricity, and so users will be more likely to take energy costs into account. Such existing leasing markets therefore offer a useful route for promoting more efficient drive products.

\subsubsection{Rebates}

Rebates are now seen primarily as a short-term measure to help stimulate the market for energy saving products, which (as in North America) was a very useful precursor to legislation on minimum motor efficiency standards.

Rebates have been successfully applied to EEMs, where they are typically set to equal the price premium of higher efficiency motors. Some money also needs to be given to the distributors to encourage them to stock such a range of motors. While giving rebates direct to the user is attractive, giving it to the manufacturers allows for a very useful "gearing" effect of the value of the rebate through the sales chain. Inevitably some EEMs will be purchased where the running hours are insufficient to give a good return on investment, but overall it is hoped that the scheme will give a good return, and in particular will stimulate interest in EEMs, as well as in EEM systems.

Rebates have also been given for VSDs, but this is a bit more involved. Most VSDs are sold for non-energy saving reasons, and so systems need to be put in place to give confidence that users are using them in approved applications only. It is likely that some form of assessment of the energy savings potential will need to be made, and if this involves proper power monitoring over a representative period (perhaps a few days), it will involve the potential equipment supplier in a lot of expense. Having received a detailed energy saving assessment, the company will then naturally seek several quotes to ensure best value for money, and so equipment suppliers may be reluctant to participate. Rebate schemes giving a reduction of perhaps $25-50 \%$ off the cost of a VSD are good for stimulating general awareness, but will still require similar levels of authorization for funding, and so the increase in demand may not be huge. A key point relating to rebates for VSDs is that they will encourage users to focus on the price of VSDs. The falling prices and 
resultant changes in the market of VSDs mean that users should also be encouraged to look for the quality of service and technical support. The long-term effect of rebates for VSDs needs to be carefully considered in order to ensure a sustainable change in the market.

\subsubsection{Other financial tools}

Bidding: Essentially an auction where electricity users bid the lowest price for rebates on electricity saving measures. Here motor users will be competing not only against each other for funds but also against other projects.

Penalties: Various forms of taxes on electricity bills to help improve the attractiveness of energy saving measures.

Loans: Low-interest loans to reduce the financing costs of energy saving equipment. However, in practice the small reduction in overall costs to the company and the paperwork involved mean that this approach has not been successful to date.

\subsection{Voluntary actions}

\subsubsection{Joint action approach}

The core of the approach is to have specific OEM sectors or system suppliers working jointly on a more standardized system characterization. Together with end-users, test laboratories and other relevant market parties, they develop more transparent performance indicators that enable quick assessment and easy comparison of overall system efficiencies (a good example of such approach is the compressed air sector in Netherlands) (Project Report, 2001; Peter Radgen and Edgar Blaustein, 2001).

\subsubsection{Negotiated agreements with end-users}

General energy efficiency related agreements: These agreements aim to improve the energy efficiency in a given sector by a specified percentage over a defined number of years. Such agreements per sector require a minimum level of coverage in a sector for sufficient impact and support. Negotiated agreements should be supported by a series of actions and or incentives, offered "in return" by the government. Such actions should facilitate the process and offer generic support tools.

Negotiated agreements on utilities. The EU has initiated the MCP that includes agreements with enterprises on improvement of electrical drive systems. This type of agreements can encompass all or most of the utility systems. They would place these higher on the agenda and make them clearly visible for management.

\subsubsection{Negotiated agreements with suppliers}

Voluntary agreements with equipment manufacturers: Voluntary agreements with equipment manufacturers could lead to more efficient systems, and to the phasing out of less efficient products. A good example is the EU/ CEMEP agreement (European Commission and European Committee of Manufacturers of Electrical Machines and Power Electronics (CEMEP), 1999). The European Commission, the European motor manufacturers and the European Committee of Manufacturers of Electrical Machines and Power Electronics (CEMEP) have agreed to a joint classification system that will enable all OEMs and other customers and users of electric motors to have a simple appreciation of the motor efficiency. The EU/CEMEP agreement established a motor efficiency classification scheme (Eff1, Eff2, Eff3), which defines minimum levels of efficiency for 2 and 4 pole induction motors, in the range 1.1$75 \mathrm{~kW}$. Additionally, the participants have the commitment of raising the market share of Eff1 and Eff2 motors by reducing the share of Eff 3 motor sales by $50 \%$ till the end of 2003. The joint target of the participants is the transformation of the European motor market toward higher efficiencies and save of electricity. The classification scheme by itself will boost the demand for Class Eff1 and Class Eff2 motors, irrespective of which voluntary agreement or mandatory regulation is adopted. However, voluntary agreements to reduce sales by an agreed percentage are inherently weak in that it is the customer who decides what motor they will buy. Voluntary agreements alone are not likely to change significantly market share.

Voluntary agreements with OEMs andlor retailers: Negotiated agreements with the equipment suppliers sector aimed at incorporating more efficient motors and motor systems should start with similar approach as Joint Actions.

\subsection{Mandatory actions}

\subsubsection{Efficiency standards}

The establishment of minimum efficiency standards for motors, for VSDs, for end-use devices and for motor systems, is an important market transformation tool. These standards will particularly be effective for OEMs, obliging them to incorporate efficient devices in their equipment. This has been the case of USA with the mandatory motors minimum efficiency standards (EPAct), enforced in October 1997.

In Europe it would be desirable the acceleration of the establishment of Eff1 motors as being the minimum standard. Moreover, the definition of an "Eff1+" efficiency level, for when Eff1 motors are the minimum efficiency allowed, should be considered.

\subsubsection{Accreditation/labeling}

Accreditation of products that satisfy specific energy saving criteria, as the Energy Star (Energy Star Award Rules and Instructions, 2000) label can be used to help 
differentiate products. An extension of this is labeling into product classes, such as the EU/CEMEP threeband motor efficiency categorization, which should be strongly promoted. Services can also be given accreditation, such as to motor repairers who adhere to a given code of practice, which will minimize motor losses during repair. Possible labels include more accurate motor labels, mandatory user-friendly labels in catalogues and advertisements (TV, newspapers, etc.), and quality marks. An efficiency-labeling scheme for pumps is not recommended, because there would be confusion on pump sets if both the motor and pump had labels with different efficiency ratings.

Labeling of compressed air systems poses some difficulties. Therefore, two approaches should be considered:

- Energy labeling for individual system components

- Energy performance labeling or certification for the entire system.

Besides helping consumers to make informed choices about efficiency products, labeling also increases competition among manufacturers to raise the efficiency of the motor system components.

\subsubsection{Laws/permits/directives}

IPPC directive (stands for integrated pollution prevention and control): IPPC directive (IPPC) is about minimizing pollution from various point sources, throughout the EU. Installations covered are required to obtain an authorization (permit) from the authorities, in the EU countries. The permits must be based on the concept of best available techniques (BAT). IPPC permits are an instrument that competent authorities in the member states can use to regulate energy efficiency issues.

EEE directive (Minimum efficiency requirements for electric equipment): This directive is currently under consideration and involves a wide range of equipment.

\subsubsection{Policing}

In the US there is currently no policing to back up the EPAct legislation. This means that it is believed there are a significant number of (largely imported) motors which are still being sold, but which do not actually reach the required efficiency level. Manufacturers who produce motors that do comply are therefore put at a significant disadvantage, and some are claiming they are losing market share and hence shedding jobs as a result.

\subsection{Research and development needs}

Research and development is needed to help bring about improved, lower cost or new energy saving products.

\subsubsection{Induction motors}

Despite being regarded as a mature product, there are still important areas for further development to reduce energy losses, including:

- lower loss steels;

- cast copper rotors;

- design for minimum stray loss; and

- optimized design of motors for inverter control.

\subsubsection{Variable speed drives}

There are two key areas requiring further $R \& D$ funding:

- lower cost power electronics; and

- easier commissioning and setting up.

The competitive global market for VSDs and the large number of manufacturers means that there is a large amount of company funded work addressing these two areas anyway, and so it is questionable whether additional funding is needed.

\subsubsection{New topologies}

- Design of "next generation" integrated motor/VSDs.

Identification of other topologies, such as permanent magnet drives, switched reluctance drives, which can offer either higher efficiency or improved speed control in applications where induction motors and PWM VSDs are not attractive.

\section{Conclusions}

Although there is a large identified savings potential, EEMs, VSDs and efficient end-use devices have not yet been widely applied in Europe because there are important obstacles which are preventing the introduction of efficient technologies in the industrial and in the services sectors. The identified electricity savings potential with the application of those technologies in the industrial and in the services sectors would translate into 45 Mton $\mathrm{CO}_{2}$ savings by 2015 , contributing to the global goal of reducing greenhouse gas emissions in the EU, which is a major strategy of the EU Energy Policy towards a European Climate Change Programme.

Split budgets, risk of failure and lack of internal incentives can be mentioned as the most important barriers for EEMs, VSDs and efficient end-use devices. Experience shows that the most successful way to promote improved EEM technologies is the combination of technical information and financial incentives. It is extremely important that technical information will address the differing needs of different personnel with different backgrounds. In what concerns motor 
efficiency improvements, research and development is also needed to bring to market new technologies and in particular to bring down the cost of existing products in order to reduce the payback times. Tools and other products alone are not sufficient and clear basic messages relating to energy saving need to be re-iterated through a wide variety of channels. Equipment suppliers and other third parties can be used to great effect to "gear up" effort to promote the market transformation of EEMs and drives.

Concerning EEMs some relevant work has already been done: the agreement between the EU and the motor manufacturers association CEMEP defines minimum levels of efficiency. However, more effort is needed to increase the user awareness and to convince them about the real advantages of EEMs, especially in the situation of failure, replacing the failed motor with an EEM rather than repairing it. The availability of the motor database EURODEEM also provides an important tool to enable motor users to make a correct selection of electric motors (EURODEEM). Concerning VSDs, the situation is quite different. The high initial cost of a VSD, especially in the lower power ranges, can make the application of VSDs not so cost effective. Therefore, there is a need for further effort in this area in order to drop the price per kilo-Watt of VSDs. Voluntary agreements with VSD and OEM manufacturers are the most effective way of promoting VSDs and improving their penetration into the market. Concerning this, the EU is at present involved in a project that aims to improve efficiencies of electric drive systems, the Motor Challenge Programme. Research and development is also needed to bring to the market the new energy-efficient technologies, such as integrated motors and VSDs and improved motor technologies, at a competitive price.

\section{References}

CADDET. Under: http://www.caddet-ee.org
Commission of the European Communities, 2000. Action plan to improve energy efficiency in the European community. Brussels, April, COM (2000) 247 final.

Compressed Air Challenge. Available at: http://www.knowpressure. org/

Energy Star Award Rules and Instructions, 2000. More and continuously updated information under http://www.epa.gov/ energystar/

European Commission, 1996a. Actions to promote energy-efficient electric motors. DG XVII, European Commission, Motors Study Group, October.

European Commission, 1996b. European energy to 2020. DirectorateGeneral for Energy (DG XVII), Spring.

EURODEEM - European Database of Energy-Efficient Motors. Joint Research Center, European Commission, http://iamest.jrc.it/ projects/eem/eurodeem.htm

European Commission and European Committee of Manufacturers of Electrical Machines and Power Electronics (CEMEP), 1999. Draft Agreement of CEMEP, June.

Final ECCP Report, 2001. European Climate Change Programme. Joint Sub-Working Group, European Commission, June, available at http://europa.eu.int/comm/environment/climat/ eccp.htm

IPPC. Available at: http://europa.eu.int/comm/environment/ippc

Macro Consulting, Inc., 1994. Overcoming barriers to the diffusion of efficient technologies. EPRI Technical Report No. TR-103527, March.

Motor Challenge Programme. Under http://energyefficiency.jrc. cec.eu.int/

Nadel, S., Shepard, M., Greenberg, S., Katz, G., de Almeida, A., 2001. Energy-efficient motor systems, 2nd Edition. American Council for an Energy-Efficient Economy, Washington, DC.

Paolo Bertoldi, Aníbal T. de Almeida, Hugh Falkner (Eds.), 2000. Energy Efficiency Improvements in Electric Motors and Drives. Springer, Berlin, ISBN 3-540-67489-6.

Peter Radgen, Edgar Blaustein, 2001. Compressed Air Systems in the European Union LOG_X. Verlag, Sttuttgart, ISBN 3-93229816-0.

Project Report, 2000. Improving the penetration of energy-efficient motors and drives. ISR-University of Coimbra, March.

Project Report, 2001. VSDs for electric motor systems. ISR-University of Coimbra, May.

Pump Life Cycle Costs, 2000. A guide to LCC analysis for pumping systems, Hydraulic Institute, Europump, US Department of Energy, Office of Industrial Technologies (OIT), DOE/GO102001-1190, December.

Reddy, A.K.N., 1991. Barriers to Improvements in Energy Efficiency. Butterworth-Heinemann, Energy Policy, December. 